\title{
PKM OLAHAN GONDO DI DESA TIMPAG, KECAMATAN KERAMBITAN, KABUPATEN TABANAN, BALI
}

\section{PKM GONDO PRODUCTS IN TIMPAG VILLAGE, KERAMBITAN SUB- DISTRICT, TABANAN DISTRICTS, BALI}

\author{
I Gusti Ayu Wita Kusumawati*, Putu Wida Gunawan, Ni Wayan Nursini, Ida Bagus Agung \\ Yogeswara \\ Universitas Dhyana Pura \\ Jl. Padangluwih Br. Tegal jaya, Kuta Utara Bali \\ *witakusumawati@undhirabali.ac.id
}

\begin{abstract}
Abstrak
Desa Timpag terkenal dengan penghasil gondo. Pemanfaatan gondo umumnya hanya dibuat sebagai sayur plecing tetapi oleh Ibu Ayu, gondo dapat diolah menjadi keripik yang rasanya digemari. Pengolahan yang bersifat tradisional menyebabkan keripik yang dihasilkan berminyak dan tidak tahan lama. Keripik gondo dipasarkan di warung-warung sekitar di desa Timpag. Kegiatan pengabdian kepada masyarakat ini bertujuan untuk membantu memperbaiki kualitas dan inovasi olahan gondo, pengurusan P-IRT, mendesain kemasan yang menarik, dan $e$ commerce melalui pelatihan dan pendampingan. Perbaikan kualitas keripik gondo melalui pengolahan dengan penggunaan vaccum frying dan pengeringan menggunakan spinner. Inovasi olahan gondo berupa puding gondo dan keripik gondo dengan variasi rasa (barbeque, keju, balado dan jagung manis). Kemasan digunakan plastik klip tebal dengan direkatkan menggunakan sealer, yang kemudian diberi label. Untuk memperluas area pemasaran produk dilakukan secara e-commerce melalui website. Hasil yang didapat setelah dilakukan pelatihan dan pendampingan terjadi peningkatan kualitas dan inovasi olahan gondo, mitra mempersiapkan pengurusan P-IRT, kemasan dan label yang menarik, area pemasaran yang semakin luas sehingga berdampak dengan peningkatan omset dan pemasukan Ibu Ayu.
\end{abstract}

Kata kunci-e-commerce, olahan gondo, spinner, vaccum frying

Abstract

Timpag village is known as gondo producer. In general, gondo is use to make sayur plecing. However, Mrs Ayu has processed gondo into a delicious chip. Traditional processing causes this chips looks greasy and have a short life during storage. Gondo chips is distributed around Timpag area especially in small vendor. The aim of this community service was to improved the quality of gondo products, taken care of P-IRT, helped to design the packaging and e-commerce training. The quality improvement of gondo chips can be employed by using vacuum frying and spinner to remove the excess oil. Gondo is also can be used to make puding and variety of flavor such as barbeque, cheese, balado and sweet corn is added to the gondo chips. The packaging was labelled and sealed using sealer. E-commerce was applied to expand the distribution of the product. The results of the training were, the quality of the products was improved, have an interesting packaging and wide distribution of the products which may result in increase of the income of Mrs Ayu.

Keywords - e-commerce, gondo products, spinner. vacuum frying

\section{PENDAHULUAN}

Desa Timpag, Kecamatan Kerambitan saat ini sedang membangun desa wisata dengan potensi daerah berupa wisata persawahan dan penangkaran burung hantu (Tyto alba). Desa Timpag memiliki luas areal pertanian sebesar 375 hektar. Tanaman Gondo (Sphenoclea zeylanica $G$ ) tumbuh di sawah sebagai tanaman gulma. Gondo dapat dihasilkan dalam jumlah yang besar dan waktu yang relatif singkat [1] Permadi, Gunadi \& Sukawijaya, 2015. Gondo yang dihasilkan desa Timpag terkenal dengan rasa yang enak dan tidak pahit dan sangat berbeda dengan yang dihasilkan oleh daerah lainnya. Keberadaan gondo yang melimpah di Desa Timpag, dimanfaatkan oleh
Ni Made Ayu Suniasih (Ibu Ayu, 45 tahun) salah warga banjar Beluluk, menjadi bubur urap gondo dan keripik gondo buk ayu. Ibu Ayu sebagai pemilik usaha, mengerjakan bisnis ini sudah hampir 2 tahun. Pada awal usahanya, baru satu bulan Ibu Ayu berjualan keripik gondo langsung banyak yang menyukai karena keripik gondo yang dihasilkan tidak lembek. Omset yang dihasilkan sebesar Rp 1.200.000,-/bulan. Keripik gondo buk Ayu selalu dijadikan suguhan para pejabat yang berkunjung ke Desa Timpag dan ikut dalam acara-acara festival di Kerambitan bahkan dua kali Ibu Ayu diliput oleh koran Bali Post berkat kesuksesannya mengolah keripik gondo. 
Pada wawancara yang dilakukan dengan mitra, mengolah keripik gondo tidaklah mudah agar didapatkan keripik yang renyah, jika tidak bisa mengolahnya maka keripik yang dihasilkan menjadi lembek. Mitra ingin sekali menjadikan keripik gondo (Gambar 1) yang diproduksi dapat dijadikan makanan khas Desa Timpag bahkan menjadi oleh-oleh untuk orang-orang yang berkunjung ke desa Timpag. Tetapi kendala pengolahan yang masih tradisional menggunakan penggorengan biasa membuat keripik yang dihasilkan memiliki kualitas yang kurang merata dan berminyak sehingga daya tahan keripik gondo tidak lama. Keripik yang diproduksi juga belum memiliki izin Pangan Industri Rumah Tangga (P-IRT) dan kemasan hanya menggunakan plastik tipis dengan diberi label seadanya. Keripik gondo ini dijual dengan harga Rp 2.000,-/bungkus dan Rp 5.000,-/bungkus (seperti yang ditampilkan pada Gambar 1), dengan berat keripik yang tidak diketahui secara pasti dalam satu kemasannya. Keripik gondo dititipkan ke warung-warung sekitar desa Timpag untuk dijual. Banyak orang mengira keripik gondo yang dijual oleh mitra adalah keripik belut, karena rasanya gurih dan enak. Selain itu mitra juga ingin menambah olahan gondo yang diproduksi olehnya supaya omset yang dihasilkan juga meningkat.

Hasil observasi dan wawancara dengan pemilik usaha keripik gondo buk Ayu, permasalahan yang dihadapi mitra adalah kualitas produk dan diversifikasi produk, izin P-IRT, kemasan produk dan pemasaran. Uraian permasalahan secara detail adalah sebagai berikut:

1. Kualitas produk dan diversifikasi produk Mitra menginginkan produk yang dihasilkan memiliki kualitas yang baik dan memiliki daya tahan yang lama. Mitra juga menginginkan produk yang dimiliki bervariasi sehingga konsumen tidak bosan dengan produk yang dijual.

2. Hygiene sanitasi tempat usaha

Mitra belum menerapkan hygiene sanitasi tempat usaha sebelum dan sesudah produksi, sehingga mitra ingin mempraktekkannya dengan benar saat memproduksi produknya.

3. Izin P-IRT

Mitra belum memiliki izin P-IRT, sehingga menginginkan produk yang diproduksi memiliki izin produksi dan edar yang resmi.

4. Kemasan produk

Kemasan sederhana yang dimiliki oleh mitra terlihat kurang menarik, sehingga mitra menginginkan memiliki kemasan dengan desain yang menarik.

5. Pemasaran

Masih terbatasnya area karena produk yang diproduksi hanya dijual melalui warung-warung sekitar Desa Timpag. Oleh karena itu mitra menginginkan perluasan area pemasaran.

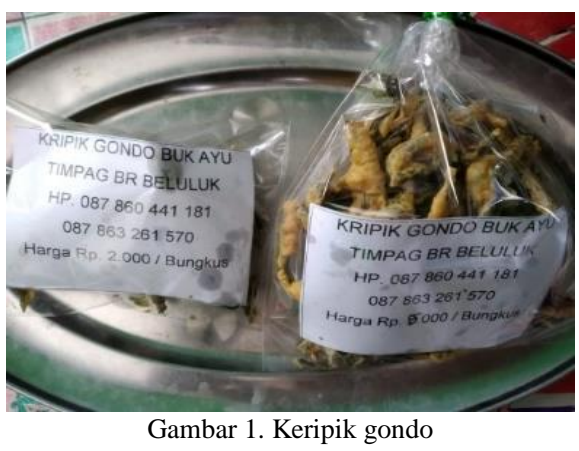

II. METODE PELAKSANAAN

Metode pelaksanaan PKM berisi langkahlangkah yang dilakukan oleh tim pengabdi untuk memberikan solusi dalam mengatasi permasalaha mitra. Tim pengabdi berasal dari program studi ilmu gizi dan teknik informatika. Solusi yang dilakukan untuk mengatasi permasalahan mitra adalah sebagai berikut:

1. Pelatihan dan pendampingan pengolahan keripik gondo dengan menggunakan vaccum frying dan diversifikasi olahan gondo.

2. Pelatihan hygiene cara bekerja yang hygiene saat mengolah produk dan selalu menjaga kebersihan area pengolahan.

3. Pelatihan pengurusan P-IRT.

4. Pelatihan dan pendampingan mengenai kemasan produk dengan desain kemasan yang menarik.

5. Pelatihan dan pendampingan mengenai pengolahan produk yang menghasilkan daya tahan produk yang lama.

6. Pelatihan dan pendampingan mengenai pembuatan web dan cara pemasaran online.

\section{Pelaksanaan kegiatan}

\section{HASIL DAN PEMBAHASAN}

Program kemitraan kepada masyarakat PKM Olahan Gondo di Desa Timpag, Kecamatan Kerambitan, Kabupaten Tabanan mendapat dukungan dari berbagai pihak yaitu Universitas Dhyana Pura dan mitra pemilik usaha keripik gondo buk Ayu, seperti yang dapat dilihat pada Gambar 2 . Pelaksanaan program adalah sebagai berikut:

1. Pelatihan dan pendampingan penggunaan metode penggorengan dengan vaccum frying dan spinner untuk meniriskan minyak hasil penggorengan.

2. Diversifikasi produk olahan gondo

3. Pelatihan cara bekerja yang hygiene saat mengolah produk dan selalu menjaga kebersihan area pengolahan

4. Pendampingan pengurusan P-IRT

5. Pelatihan dan pendampingan mengenai kemasan produk dengan metode sealer 
6. packaging dengan desain kemasan yang menarik.

7. Pelatihan dan pendampingan mengenai pengolahan produk yang menghasilkan daya tahan produk yang lama.

8. Pelatihan dan pendampingan mengenai pembuatan web dan cara pemasaran online.

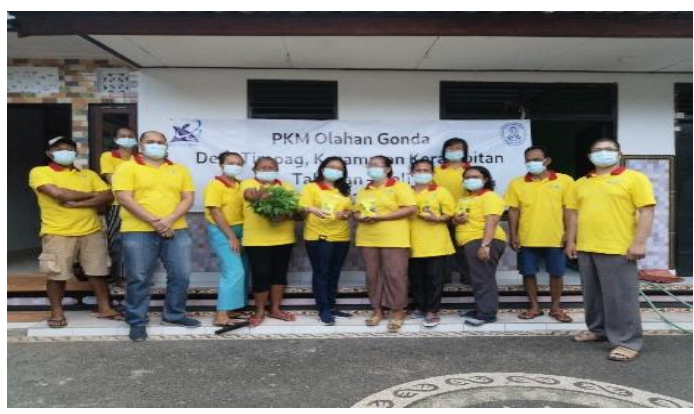

Gambar 2. Tim pelaksana PKM dan mitra

1. Pelatihan dan pendampingan penggunaan metode penggorengan dengan vaccum frying dan spinner untuk meniriskan minyak hasil penggorengan

Pelatihan proses penggorengan menggunakan vaccum frying dan proses penirisan minyak hasil penggorengan dengan menggunakan spinner melibatkan pemilik usaha dan para karyawan keripik gondo. Tim PKM memfasilitasi alat vaccum frying dan spinner. Ibu Ayu sebagai pemilik usaha dan para karyawan sangat antusias mengikuti pelatihan karena penggunaaan vaccum frying mempercepat proses pengolahan keripik gondo yang mereka produksi. Sebelum menggunakan vaccum frying, Ibu Ayu membutuhkan waktu 1,5 jam untuk memproduksi 1 $\mathrm{kg}$ keripik gondo, tetapi setelah menggunakan vaccum frying waktu produksi menjadi 20 menit saja. Pelatihan penggunakan spinner dilakukan untuk meniriskan minyak sisa yang menempel masih menempel di keripik gondo. Sebelumnya mitra hanya menggunakan saringan dan kukusan untuk meniriskan minyak, sehingga minyak yang menempel di keripik gondo cukup banyak. Hasil proses pengolahan keripik gondo sebelum dan sesudah menggunakana alat vaccum frying dan spinner dapat dilihat pada Gambar 3.

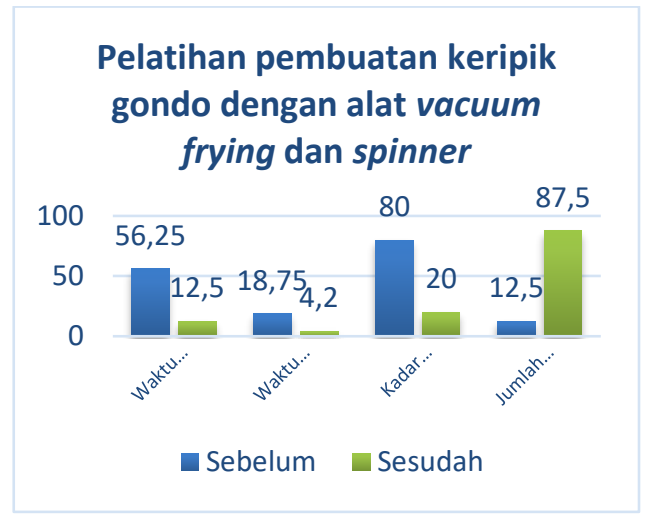

Gambar 3. Hasil proses pengolahan keripik gondo sebelum dan sesudah menggunakana alat vaccum frying dan spinner

Adanya bantuan alat vaccum frying dan spinner sangat menunjang proses produksi mitra [2] Chotimah et al., 2019), sehingga produk yang dihasilkan lebih berkualitas dan layak jual. Bantuan yang diberikan oleh tim PKM dapat dilihat pada Gambar 4. Hal ini dapat membantu mitra untuk meningkatkan omset dan pendapatannya. Pelatihan dan pendampingan serta manfaat yang diperoleh mitra selama kegiatan ini ditunjukkan pada Gambar 5.

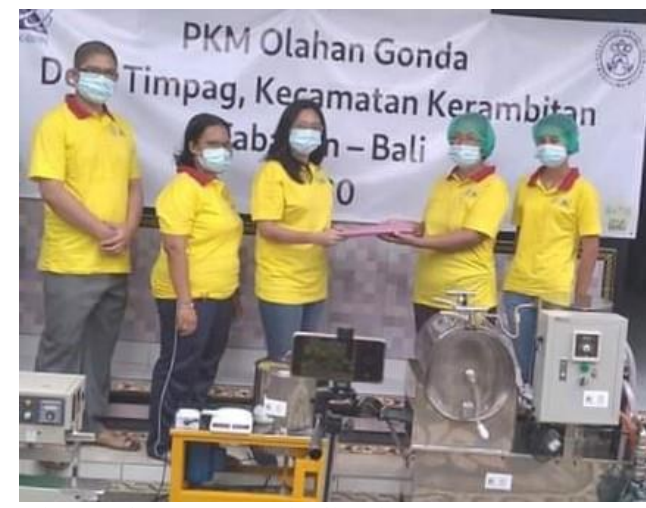

Gambar 4. Tim PKM memberikan bantuan vaccum frying dan spinner untuk proses produksi
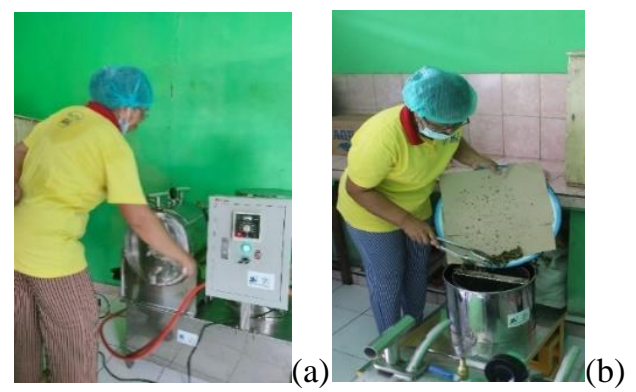

Gambar 5. Pelatihan penggunaan alat vaccum frying (a); spinner dan minyak hasil dari keripik yang dispinner (b)

\section{Diversifikasi produk olahan gondo}

Diversifikasi produk olahan gondo dilakukan untuk menambah pilihan konsumen terhadap produk yang diproduksi oleh Ibu Ayu. Kegiatan ini diberikan kepada 8 orang yang terdiri dari Ibu Ayu sebagai pemilik usaha dan 7 orang karyawan. Olahan yang dibuat pada pelatihan yaitu puding gondo. Puding berbahan dasar sayuran perlu dilakukan uji organoleptik untuk mengetahui tingkat kesukaan panelis terhadap puding yang dihasilkan (Misnaiyah et al., 2018). Mitra menyukai puding yang dipraktekkan oleh tim PKM, karena rasanya yang tidak pahit walaupun masih ada rasa gondo, teksturnya lembut, aromanya harum, dan kenampaknya asli gondo. Hasil uji organoleptik puding gondo dapat dilihat pada Gambar 6. Gambar puding gondo dapat dilihat pada Gambar 7. 


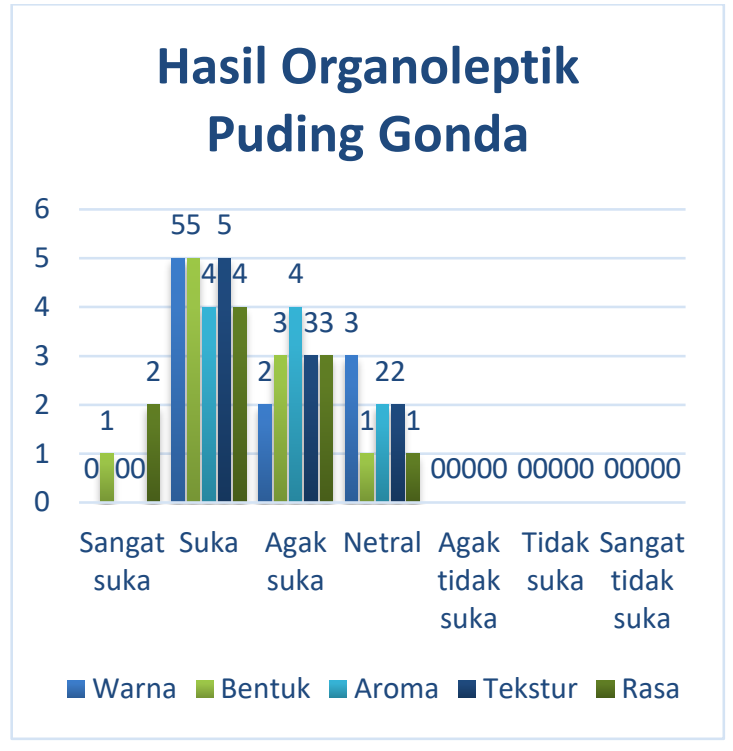

Gambar 6. Hasil uji organoleptik puding gondo

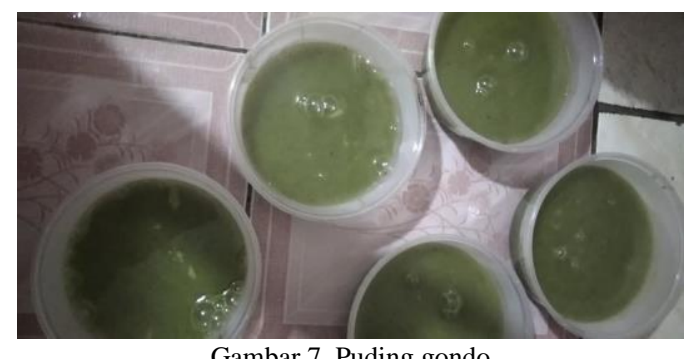

Gambar 7. Puding gondo

Diversifikasi keripik gondo dilakukan dengan menambahkan variasi rasa pada keripik gondo (Herawati et al., 2019), seperti yang ditampilkan pada Gambar 8. Sebelumnya keripik gondo yang diproduksi mitra hanya memiliki rasa original. Sesudah pelatihan keripik gondo memiliki tambahan rasa baru yaitu barbeque, keju, balado dan jagung manis. Mitra merasa senang dengan adanya penambahan rasa karena gondo yang memiliki rasa sedikit pahit bisa disamarkan dengan penambahan rasa tersebut.

Keripik gondo yang dihasilkan sebelum pendampingan belum memiliki berat yang seragam. Tim PKM memfasilitasi dengan pemberian timbangan digital, sehingga setelah pendampingan keripik gondo memiliki berat yang seragam.

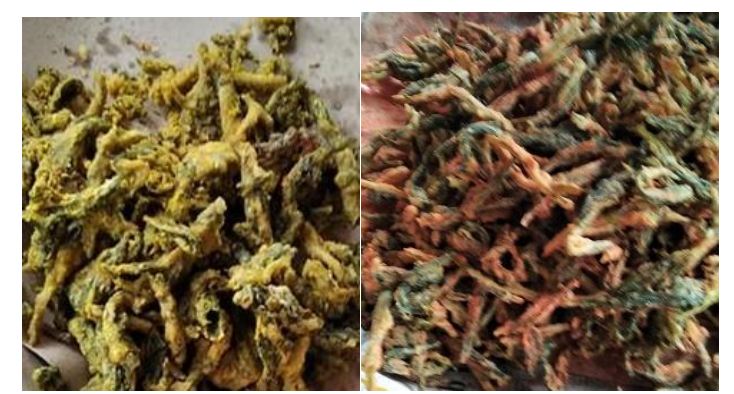

Gambar 8. Keripik gondo aneka rasa

\section{Pelatihan cara bekerja yang hygiene saat mengolah produk dan selalu menjaga kebersihan area pengolahan}

Pelatihan cara bekerja yang hygiene saat mengolah produk bermanfaat untuk menjaga higienitas produk yang dihasilkan. Kegiatan pelatihan personal hygiene meliputi cara mencuci tangan sebelum dan sesudah produksi, menggunakan hair cap dan sarung tangan saat memproduksi produk olahan, menggunakan pakaian yang bersih, tidak menggunakan aksesoris berlebihan selama produksi pengolahan dan menggunakan masker dan handsanitizer [5] Departemen Kesehatan RI, 2014). Tim PKM memberikan fasilitas pelatihan berupa sabun cuci tangan, hair cap, sarung tangan, handsanitizer, dan masker. Narasumber mempraktekan gerakan mencuci tangan yang benar kemudian diikuti oleh masing-masing anggota mitra secara bergantian selama 20 detik.

Pelatihan hygiene peralatan dilakukan untuk memastikan alat-alat yang digunakan selama proses produksi dalam kondisi yang bersih. Pelatihansanitasi area pengolahan keripik gondo dilakukan sebelum dan sesudah proses pengolahan. Mitra dilatih pembiasaan melakukan kegiatan pembersihan seperti mencuci dan mengelap alat-alat yang digunakan berproduksi serta menyapu dan mengepel lantai area produksi. Hasil pelatihan penerapan hygiene dan sanitasi sebelum dan sesudah pelatihan dapat dilihat pada Gambar 9.

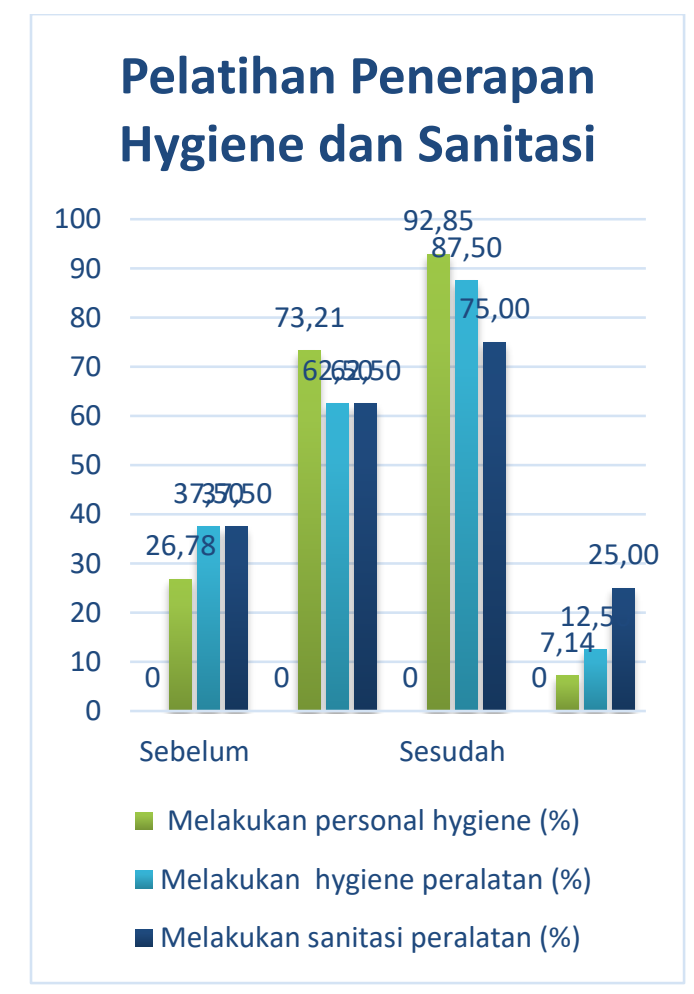

Gambar 9. Hasil penerapan hygiene dan sanitasi sebelum dan sesudah pelatihan 
Tim PKM juga memberikan pelatihan tambahan berupa keselamatan kerja. Pelatihan keselamatan kerja penting untuk diketahui dan dilakukan oleh mitra untuk mencegah terjadinya kecelakaan kerja. Narasumber mempraktekan cara bekerja yang aman dan cara mengatasi serta memberi pertolongan pertama jika terjadi kecelakaan kerja. Tim PKM melakukan pre test dan post test kepada mitra untuk mengukur tingkat pengetahuan dan pemahaman mengenai keselamatan kerja. Hasil pre test dan post test keselamatan kerja ditunjukkan pada Gambar 10.

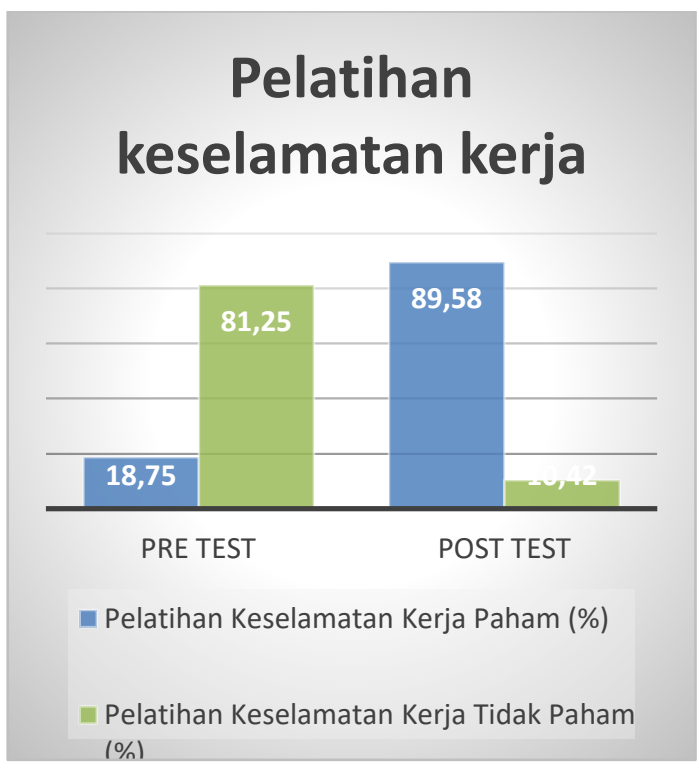

Gambar 10. Hasil pre test dan post test keselamatan kerja

\section{Pendampingan pengurusan $P$-IRT}

Pelatihan pengurusan P-IRT dilakukan agar produk yang dihasilkan memiliki izin produksi dan edar. Tim pengabdi memfasilitasi dan membantu pengurusan P-IRT ke Dinas Kesehatan Kabupaten Tabanan. Narasumber menjelaskan dokumendokumen yang harus disiapkan untuk pengurusan $\mathrm{P}$ IRT.

Ibu Ayu selaku pemilik usaha mempersiapkan dokumen-dokumen yang diperlukan untuk pengurusan yang meliputi fotokopi KTP, denah bangunan, denah lokasi, pas foto berwarna $4 \times 6$ serta surat izin usaha. Sedangkan untuk rancangan label untuk kemasan difasilitasi oleh tim PKM.

\section{Pelatihan dan pendampingan mengenai kemasan produk dengan metode sealer packaging dengan desain kemasan yang menarik}

Pelatihan dan pendampingan kemasan produk dengan menggunakan plastik [6] Mareta dan Shofia, 2011, sealer dan desain yang menarik dilakukan agar konsumen lebih tertarik terhadap produk olahan yang dijual. Tim pengabdi memfasilitasi alat sealer dan memberikan label desain yang menarik. Tim pengabdian juga memberikan nama brand untuk keripik gondo. Tim PKM memberi brand gotik (gondo Timpag kriuk). Mitra dilatih cara menggunakan sealer. Sebelum pelatihan, mitra mengemas keripik gondo menggunakan plastik tipis yang diberi staples. Setelah pelatihan, mitra mengemas menggunakan plastik tebal dan direkatkan menggunakan sealer.

Mitra juga diberikan label kemasan yang menarik. Sebelum pendampingan, mitra menggunakan label yang terbuat dari kertas yang diketik. Setelah pendampingan, mitra menggunakan label stiker yang dibuat dengan warna dan bentuk yang menarik. Adanya bantuan pemberian label kemasan yang menarik dapat meningkatkan ketertarikan konsumen terhadap keripik gondo, sehingga omset dan pendapatan mitra menjadi meningkat. Gambar yang menunjukkan kemasan dan label keripik gondo sebelum dan sesudah pelatihan ditampilkan pada Gambar 11.
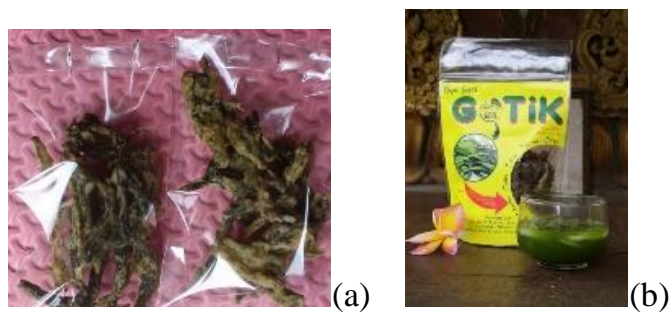

Gambar 11. Kemasan dan label keripik gondo sebelum (a) dan sesudah (b) pelatihan dan pendampingan oleh tim PKM

6. Pelatihan dan pendampingan mengenai pengolahan produk yang menghasilkan daya tahan produk yang lama

Pelatihan dan pendampingan mengenai pengolahan produk yang menghasilkan daya tahan produk yang lama dilakukan untuk memperpanjang umur simpan keripik gondo. Alat vaccum frying, spinner dan sealer digunakan untuk menghasilkan ketahanan produk yang lebih lama [7] Asgar dan Rahayu, 2014; Chotimah et al., 2019. Sebelum pelatihan, mitra menggunakan wajan untuk menggoreng gondo, saringan untuk meniriskan keripik gondo dan stapler untuk merekatkan kemasan. Cara ini menghasilkan banyak minyak yang masih menempel pada keripik gondo sehingga produk hanya bertahan selama 10 hari. Setelah pelatihan dengan alat-alat yang difasilitasi oleh tim PKM, keripik gondo tidak berminyak dan mampu bertahan selama 3 bulan (seperti yang terlihat pada Gambar 12).

Adanya bantuan alat vaccum frying, spinner dan sealer telah membantu proses produksi mitra. Produk yang dihasilkan oleh mitra lebih berkualitas, 
tahan lama dan layak jual. Hal ini dapat membantu mitra dalam meningkatkan omset dan pendapatan.

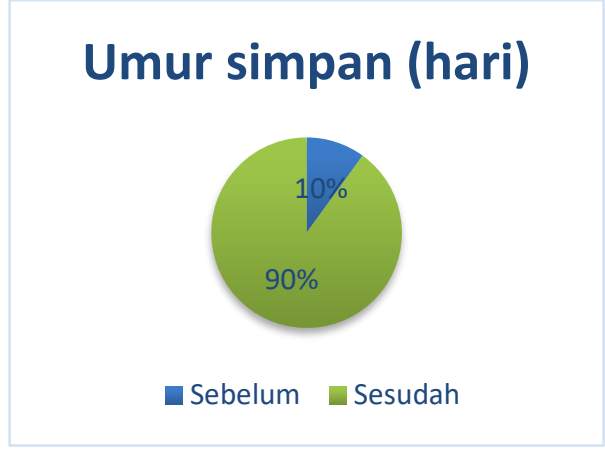

Gambar 12. Daya tahan keripik go+sebelum dan sesudah pelatihan

7. Pelatihan dan pendampingan mengenai pembuatan web dan cara pemasaran online

Tim pengabdi melakukan pelatihan dan pendampingan bagi mitra untuk memasarkan produk secara online. Pelatihan dan pendampingan ini dilakukan dengan membantu mitra untuk membuat website Gotikbali.my.id dan memasarkan di market place sebagai ajang promosi bagi mitra pengabdian. Website pemasaran online untuk produksi olahan gondo masih dalam proses pengembangan secara bertahap. Area pemasaran keripik gondo mengalami perluasan. Sebelumnya pemasaran hanya di sekitar Desa Timpag, sedangkan setelah pelatihan area pemasaran menjangkau area Tabanan. Hasil sebelum dan sesudah pelatihan dan pendampingan pemasaran dapat dilihat pada Gambar 13.

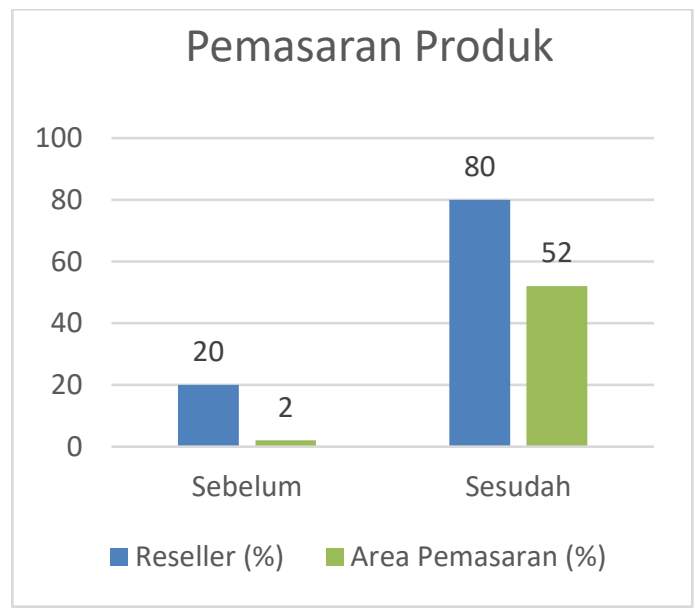

Gambar 13. Hasil sebelum dan sesudah pelatihan dan pendampingan pemasaran

\section{IV.KESIMPULAN}

Kegiatan pengabdian ini menghasilkan produk yang mengalami peningkatan kualitas dan daya tahan produk, diversifikasi produk olahan gondo, kemasan dan label yang menarik, serta perluasan area pemasaran yang berdampak pada peningkatan omset dan pendapatan mitra.

\section{UCAPAN TERIMAKASIH}

Ucapan terimakasih disampaikan kepada Direktorat Riset dan Pengabdian kepada Masyarakat Direktorat Jenderal Penguat Riset dan Pengembangan Kementrian Riset teknologi dan Pendidikan Tinggi sesuai dengan surat perjanjian pelaksanaan bantuan program kemitraan masyarakat Nomor B/117/E3/RA.00/2020 tanggal 28 Januari 2020.

\section{DAFTAR PUSTAKA}

[1] Permadi, I.W.A., Gunadi, I.G.A., dan Sukewijaya, I.M. 2015. Identifikasi Karakter Agronomi Tanamanan Gonda (Sphenoclea zeylanica Gaertn) di Kabupaten Jembrana, Bali. Agrotrop 5(1): 43-54).

[2] Chotimah, H.E.N.C., Kusumadati, W., Taufik, E.N., dan Sunainah. 2019. Pemberdayaan Kelompok Wanita Tani Melalui Pembuatan Keripik Sayuran Metode Vaccum Frying. Jurnal Pengabdi 2(1): 124-136.

[3] Misnaiyah., Indani., Kamal, R. 2018. Daya Terima Konsumen Terhadap Puding Brokoli (Brasicca Oleracea). Jurnal Ilmiah Mahasiswa Pendidikan Kesejahteraan Keluarga 3(1): 54-62.

[4] Herawati, S., Irawan, W., dan Mujiono. 2019. Pelatihan Membuat Keripik Singkong dan Talas di Desa Brongkal, Kecamatan Pagelaran, Kabupaten Malang. Jurnal Akses Pengabdian Indonesia 4(1): 34-41.

[5] Departemen Kesehatan RI. 2004. Higiene Sanitasi Makanan dan Minuman

[6] Mareta, D.T., dan Shofia, N.A. 2011. Pengemasan Produk Sayuran Dengan Bahan Kemas Plastik Pada Penyimpanan Suhu Ruang Dan Suhu Dingin. Mediagro 7(1): 26-40.

[7] Asgar, A; dan Rahayu, S.T. 2014. Pengaruh Suhu Penyimpanan dan Waktu Pengkondisian Untuk Mempertahankan Kualitas Kentang Kultivar Margahayu. Berita Biologi 13(3): 283293. 